\title{
An inventory model of two-warehouse system with variable demand dependent on instantaneous displayed stock and marketing decisions via hybrid RCGA
}

\author{
A. K. Bhunia ${ }^{\text {a }}$ P. Pal ${ }^{\text {b* }}$, S. Chattopadhyay ${ }^{\mathrm{c}}$ and B. K. Medya ${ }^{\mathrm{d}}$ \\ ${ }^{a}$ Department of Mathematics, The University of Burdwan, Burdwan-713104, India \\ ${ }^{b}$ Department of Computer Science \& Engineering, Hooghly Engineering \& Technology College, Hooghly-712103, India \\ ${ }^{c}$ Department of Information Technology, Jadavpur University,India \\ ${ }^{d}$ Department of Information Technology, N.I.T., Kolkata,India
}

A R T I C L E I N F O A S T R A T

Article history:

Received 15 August 2010

Received in revised form

20 November 2010

Accepted 25 November 2010

Available online

25 November 2010

Keywords:

Inventory

Two- warehouse

Variable Demand

Genetic Algorithm

Marketing Research

\begin{abstract}
In this paper, a single item deterministic inventory model with two separate warehouses called owned warehouse/show-room (OW) and rented warehouse (RW) is developed. The proposed model of this paper also considers a realistic assumption regarding the storage capacity of the rented warehouse. Demand is a function of selling price, advertisement of an item and displayed inventory level in OW. The stocks of RW are shipped to OW under bulk release pattern where shortages are not allowed. We discuss different scenarios of the proposed model to address relative size of stock dependency parameters and the capacity of owned warehouse. For each scenario, the corresponding problem is formulated as a constrained mixed integer nonlinear programming problem with three integer and two non-integer variables and a real coded genetic algorithm (RCGA) is developed to solve the resulted problem. The proposed model of the paper is also examined using some numerical examples and sensitivity analysis is performed.
\end{abstract}

\section{Introduction}

The primary assumption in most of the inventory problems is that there is an owned warehouse with unlimited storage. However, in reality, this assumption does not hold as a warehouse normally has limited storage capacity. On the other hand, when the cost of procuring goods is higher than the inventory related cost or the attractive price discount for bulk purchase is available or the demand of the items is very high, the inventory management procures a large quantity of items at a time. This large quantity of items cannot be stored in the existing warehouse called owned warehouse (OW) with limited storage capacity. Then for storing the excess items, one or more warehouse called rented

* Corresponding author. Tel: +91-3213-254112 /+91-9614325369

E-mail: p5_pal@yahoo.co.in (P.Pal)

(c) 2011 Growing Science Ltd. All rights reserved.

doi: 10.5267/j.ijiec.2010.07.008 
warehouse (RW) is rented either away from or near to OW and these items are sold to the customers at OW only. Generally, the inventory cost of RW is greater than OW. Hence, to reduce the inventory carrying cost, the items are stored first in OW and the excess stock is stored in RW. Further, the stocks of RW are cleared first by transferring the stock from RW to OW in either continuous or bulk release pattern. This inventory system is known as two-storage inventory system.

During the last three decades, several researchers have developed different types of two-storage inventory models. Hartely (1976) first introduced this type of purchasing inventory model in his book. In his formulation, assuming higher holding cost in RW than that in OW and ignoring the transportation cost for transferring the goods from RW to OW, he proposed a heuristic procedure to determine the optimal order quantity. Sarma $(1983,1987)$ extended Hartely's model considering the fixed transportation cost, independent of the quantity transferred from RW to OW for nondeteriorating as well as deteriorating items. However, in both models, he did not consider shortages. During the past two decades, there have been extensive works dedicated to two-warehouse inventory models under different scenarios (Dave, 1988; Pakkala \& Achary, 1992-a, 1992-b; Goswami \& Chowdhuri , 1992; Bhunia \& Maiti, 1994, 1995, 1998; Benkherouf, 1997; Zhou, 1998, 2003; Kar et al., 2001; Zhou \& Yang, 2003; Yang, 2004, 2006; Pal et al., 2005; Das et al., 2007; Dye et al., 2007; Dey et al., 2008; Niu \& Xie, 2008; Rong et al., 2008; Mondal et al., 2007; Jaggi \& Arneja, 2011).

In the present competitive market situation, a product is promoted to the customers through the advertisement in the well-known print/electronic media and also through the sales representatives and/or by the glamorous display of that item in large numbers with the help of modern light and electronic arrangements. This type of advertisement and glamorous display of items increase its demand among the public. Considering only the effects of advertising and price variation on demand rate, many researchers developed different types of inventory models (Kotler, 1971; Ladany \& Sternleib, 1974; Subramanyam \& Kumaraswamy, 1981; Urban , 1992; Goyal \& Gunasekaran, 1995; Abad, 1996; Luo, 1998; Mandal et al., 1989). Again, in the last few years, very few researchers developed inventory models incorporating demand rate depending only on displayed stock level. Baker and Urban (Baker \& Urban, 1985) were first who enlightened that demand rate would be declined along with the displayed inventory level throughout the entire cycle. They developed an inventory model for polynomial type of demand rate. Mandal and Phaujdar (Mandal \& Phaujdar, 1989) proposed independently a production inventory model where demand rate is a general function of the on-hand stock level during the stock-in and stock-out period. Dutta and Pal (Dutta \& Pal, 1990) modified the model of Baker and Urban (Baker \& Urban, 1985) by assuming that demand rate of an item depends on displayed inventory level until a given level is achieved once it becomes constant. Since then, very few researchers have given considerable attention on inventory problems with displayed inventory level dependent demand rate (Urban, 1992, 1995; Pal et al., 1993; Giri et al., 1996; Padmanabhan and Vrat , 1995; Sarkar et al., 1997; Giri \& Chaudhuri, 1998).

To the best of our knowledge, only Mondal et al. ( Mondal, 2007) and Pal et al. (Pal et al., 2004, 2006) considered the effects of displayed stock level, selling price and advertisement on demand in developing their inventory models. However, in their formulation, the frequency of advertisement in demand rate was a fixed value. In the inventory control theory, the transportation cost for replenishing the items plays an important role and it must be taken into account with other inventory related costs. In most of the existing literature, the transportation cost is not considered separately, it is included in the replenishment cost which is independent of the order quantity. Different transportation alternatives have various speed, reliability and cost characteristics. Hence, the transportation cost depends on the order quantity. As a result, we cannot ignore this cost item from the analysis of the inventory system. Recently, very few researchers incorporated this cost into the lot-size determination analysis. Baumol and Vinod (Baumol \& Vinod, 1970) first considered an inventory model of freight transport where the order quantity and transportation alternative can be jointly determined. Constable and Whybark (Constable \& Whybark, 1978) assumed that the transportation cost per unit is independent of the order quantities. Buffa and Munn (Buffa \& Munn, 
1989) developed the model considering the transportation cost per unit to be a negative exponential function of the order quantity. Anily and Federgruen (1990) considered the transportation cost in terms of truck loading cost.

In this paper, a deterministic two-warehouse inventory model for single item is developed by removing the existing unrealistic assumption regarding the storage capacity of the rented warehouse and it is considered as finite. The demand rate of the system is dependent on the selling price of the item, frequency of advertisement in the popular media and displayed inventory level in the showroom or OW within a range and beyond this range, the rate is constant with respect to the displayed inventory level. The stocks of RW are transferred to OW under bulk release fashion and the associated transportation cost is taken into account. For replenishing the items, the transportation cost depends on the ordering quantity as well as the distance from the supplier's store to the show-room and shortages are not allowed. According to the relative size of displayed inventory level dependency parameters and the capacity of the show-room, different scenarios of the system are clearly discussed. For each scenario, the corresponding problem is formulated as a constrained mixed integer nonlinear programming problem. To solve the said problem, we develop a real coded hybrid genetic algorithm by combining advanced real coded genetic algorithm and multi-section criteria of search region for continuous decision variables. The problems of different scenarios are solved for a given numerical example to illustrate the implementation of the proposed model. Finally, based on the example, sensitivity analyses are performed to study the effect of changes of different parameters of the proposed inventory system on the best found value of the optimal profit.

\section{Assumptions and Notations}

\subsection{Assumptions}

The following assumptions are used to derive the proposed mathematical model:

(i) Replenishments are instantaneous with a known constant lead time.

(ii) The inventory planning horizon is infinite and the inventory system involves only one item and one stocking point.

(iii) Only a single order occurs at the beginning of each cycle and the entire lot is delivered in one batch.

(iv) Shortages are not allowed.

(v) The replenishment cost (ordering cost) is constant excluding the transportation cost for replenishing the items.

(vi) There is no quantity discount.

(vii) After replenishment, first OW is filled completely and the excess items are stored in RW. In this situation, an additional transportation cost is incurred for special dispatch of goods to RW.

(viii) The transportation cost is constant for a transport vehicle with a given capacity even if the quantity shipped is less than a transport vehicle load by some quantity.

\subsection{Notations}

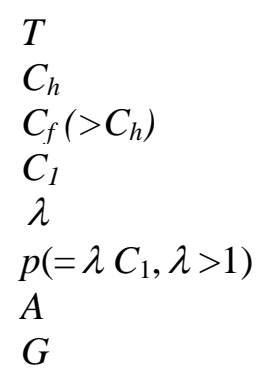

Cycle length

Inventory carrying cost in OW per unit per unit time

Inventory carrying cost in RW per unit per unit time

Purchase cost per unit

Mark-up rate

Selling price per unit

Frequency of advertisement per cycle

Cost for each advertisement 
Fixed transportation cost for $P_{1}$ units

$L_{j-1}^{\prime}$

$L_{j}^{\prime}$

$C_{t}=C_{t j}$

$C_{t F}=C_{t F j}$

$C_{a d}$

$U_{j}$

$C_{t j}$

$U_{j}=\left[C_{t j} / C_{t F j}\right]$

Additional transportation cost per unit beyond $P_{1}$ units

Consumption period of $\mathrm{K}$ units

Consumption period of first $i K$ units i.e., $t_{i}^{\prime}=i t_{1}$

Storage capacity of owned warehouse (OW)

Storage capacity of rented warehouse (RW)

Order quantity of the system

Consumption period of the last $W-K+S^{\prime}$ units in OW

Instantaneous stock level at time $t$

Capacity of a transport vehicle

Distance between the show-room/OW and the source of the items/ commodities from where items/ commodities are to be transported

Lower cut off distances

Upper cut off distances

Transportation cost for full load of transport vehicle where $L_{j-1}^{\prime} \leq L \leq L_{j}^{\prime}$ for $j=1,2,3, \cdots$

Transportation cost per unit item where $L_{j-1}^{\prime} \leq L \leq L_{j}^{\prime}$ for $j=1,2,3, \cdots$

Additional transportation cost per item incurred for special dispatch of goods to the rented warehouse RW

Upper break point for $L_{j-1}^{\prime} \leq L \leq L_{j}^{\prime}$

Fixed transportation cost for the whole quantity or some quantity less than $K^{\prime}$ but above $U_{j}$

Greatest integer value which is less than or equal to $C_{t j} / C_{t F j}$

\section{The Demand Function}

According to Baker and Urban (Baker \& Urban, 1985), the demand rate of an item is a function of the instantaneous stock level and reported that this rate is not constant. It changes along with the stock level of the show-room/shop throughout the order cycle. Therefore, the higher stock level will cause the greater demand rate during the beginning of the cycle and this is not always true. There are many cases to motivate the customers to purchase the stock displayed in the show-room/shop with a glamorous fashion with the help of modern light and electronic equipments. Therefore, the demand of customers varies with the displayed inventory level, not based on the total inventory of the shop. It also depends on the effect of marketing policies and conditions such as the price variations and the advertisement of the item.

The deterministic demand rate $D(A, p, q)$ of an item is a known function of marketing parameters with the frequency of advertisement $(A)$, the selling price $(p)$ and the displayed inventory level in the show-room / shop within the inventory level $S_{0}$ to $S_{1}$ and beyond this range it becomes constant with respect to the displayed inventory level. The functional form of this type demand is as follows,

$$
D(A, p, q)=\left\{\begin{array}{llc}
f\left(A, p, S_{1}\right) & \text { for } & q>S_{1} \\
f(A, p, q) & \text { for } & \mathrm{S}_{0}<q \leq S_{1}, \\
f\left(A, p, S_{0}\right) & \text { for } & 0 \leq q \leq S_{0}
\end{array}\right.
$$


where $f(A, p, q)$ is a function of $A, p, q$.The functional form of the stock-dependent demand rate may be of different types. These may be power form $\left(\alpha q^{\beta}\right)$, exponential form $[\alpha \exp (\beta q)]$, linear form $(\alpha+\beta q)$, quadratic form $\left(\alpha+\beta q+\gamma q^{2}\right)$ with respect to the instantaneous stock-level. The power form demand rate results zero demand as the stock-level tends to zero but the demand of an item cannot be zero. Generally, demand rate does not fully depend on the instantaneous displayed stocklevel for many reasons such as goodwill, good quality, and genuine price-level of the goods where a limited number of customers arrive to purchase the goods. Hence, the demand rate of an item of a particular shop will be more appropriate if the linear form of the demand rate with respect to the stock-level is considered. In this paper, we shall consider the linear form of the displayed inventory, the selling price of an item and exponential form of the frequency of the advertisement for $f(A, p, q)$. Suppose we have $f(A, p, q)=A^{\gamma}(a-b p+c q)$ where $a, b, c, \gamma \geq 0$.

\section{Transportation Costs}

When the order quantity is greater than the load of one transport vehicle, the order quantity $S$ can be expressed as follows,

$S=m K^{\prime}+\mu q^{\prime}$ where $m=0,1,2,3, \ldots ; \mu=0$ or 1 and $q^{\prime}<K^{\prime}$. In this case, two situations may arise,
(i) $m K^{\prime}<S \leq m K^{\prime}+U_{j}$,
(ii) $m K^{\prime}+U_{j}<S \leq(m+1) K^{\prime}$.

For replenishing the items, the transportation cost $T C_{1}$ for a particular distance $L\left(L_{j-1}^{\prime} \leq L \leq L_{j}^{\prime}\right)$ is given by

$T C_{1}=\left\{\begin{array}{clc}m C_{t j}+\left(S-m K^{\prime}\right) C_{t F j}+C_{a d}(S-W) & \text { where } \quad m K^{\prime}<S \leq m K^{\prime}+U_{j} \\ (m+1) C_{t j}+C_{a d}(S-W) & \text { where } m K^{\prime}+U_{j}<S \leq(m+1) K^{\prime}\end{array}\right.$

Again, the transportation cost $T C_{2}$ for transferring the items/goods from RW to $\mathrm{OW}$ in $n$ shipments is given by

$T C_{2}=\left\{\begin{array}{ccc}(n-1)\left\{a^{\prime}+b^{\prime}\left(K-P_{1}\right)\right\}+a^{\prime}+b^{\prime}\left(S^{\prime}-P_{1}\right) & \text { when } & \mathrm{K}, \mathrm{S}^{\prime}>\mathrm{P}_{1} \\ (n-1)\left\{a^{\prime}+b^{\prime}\left(K-P_{1}\right)\right\}+a^{\prime} & \text { when } & \mathrm{K}>\mathrm{P}_{1}, S^{\prime} \leq P_{1} \\ n a^{\prime} & \text { when } & \mathrm{K}, \mathrm{S}^{\prime} \leq \mathrm{P}_{1}\end{array}\right.$

Hence, the total transportation cost of the system is given by $C_{\text {tran }}=T C_{1}+T C_{2}$.

\section{Mathematical Formulation}

Initially, an enterprise purchases $S(S>W)$ units, of which $W$ units are stored in the owned warehouse (OW) and the remaining $(S-W)$ units in the rented warehouse (RW). At first, the stocks of OW are used to meet the customer's demand until the stock level in OW drops to $(W-K)$ units at the end of time $t_{1}$. At this stage, $K(K \leq W)$ units from RW are transported to OW so that the stock level of OW again becomes $W$ to meet further demands and the process continues for ( $n-1)$ such shipments. In the last shipment, the remaining $S^{\prime}\left(S^{\prime} \leq K\right)$ units in RW are transported to OW. After the last shipment, the stock level of OW will be $\left(W-K+S^{\prime}\right)$ units which are used as usual to satisfy the demand during $\left[t_{n}, T\right]$. This entire cycle is repeated after each scheduling period $T$. 
To analyze this model, nine different scenarios (first 3 scenarios for $S_{1}>W$ and last 6 scenarios for $\left.S_{1}<W\right)$ may arise according to the relative size of $S_{0}, S_{1}, W$ and the transported amounts $K$ and $S^{\prime}$ per shipment.

Scenario-1: $S_{1}>W, S_{0}>W-K$ and $W-K+S^{\prime}>S_{0}$

Scenario-2: $S_{1}>W, S_{0}>W-K$ and $W-K+S^{\prime}<S_{0}$

Scenario-3: $S_{1}>W, S_{0}<W-K$

Scenario-4: $S_{1}<W, S_{0}>W-K$ and $W-K+S^{\prime}>S_{1}$

Scenario-5: $S_{1}<W, S_{0}>W-K$ and $S_{0}<W-K+S^{\prime}<S_{1}$

Scenario-6: $S_{1}<W, S_{0}>W-K$ and $W-K+S^{\prime}<S_{0}$

Scenario-7: $S_{1}<W, S_{0}<W-K$ and $W-K+S^{\prime}>S_{1}$

Scenario-8: $S_{1}<W, S_{0}>W-K$ and $W-K+S^{\prime}<S_{1}$

Scenario-9: $S_{1}<W-K$

Note that $S_{0}$ may be greater than $W$. In that case, the demand rate will be constant with respect to the displayed stock-level in the show-room OW which is in contradiction to the pattern of proposed demand rate. As a result, we shall reject the Case $S_{0}>W$. Now, we shall study the Scenario-1 in details.

Scenario-1: $S_{1}>W, S_{0}>W-K$ and $W-K+S^{\prime}>S_{0}$

In this scenario, the displayed stock-level dependent demand rate is observed when the inventory level drops from $W$ to $S_{0}$ and beyond $S_{0}$, it is constant. The pictorial representations of the inventory system in RW and OW are given in Fig. 1 and Fig. 2, respectively.

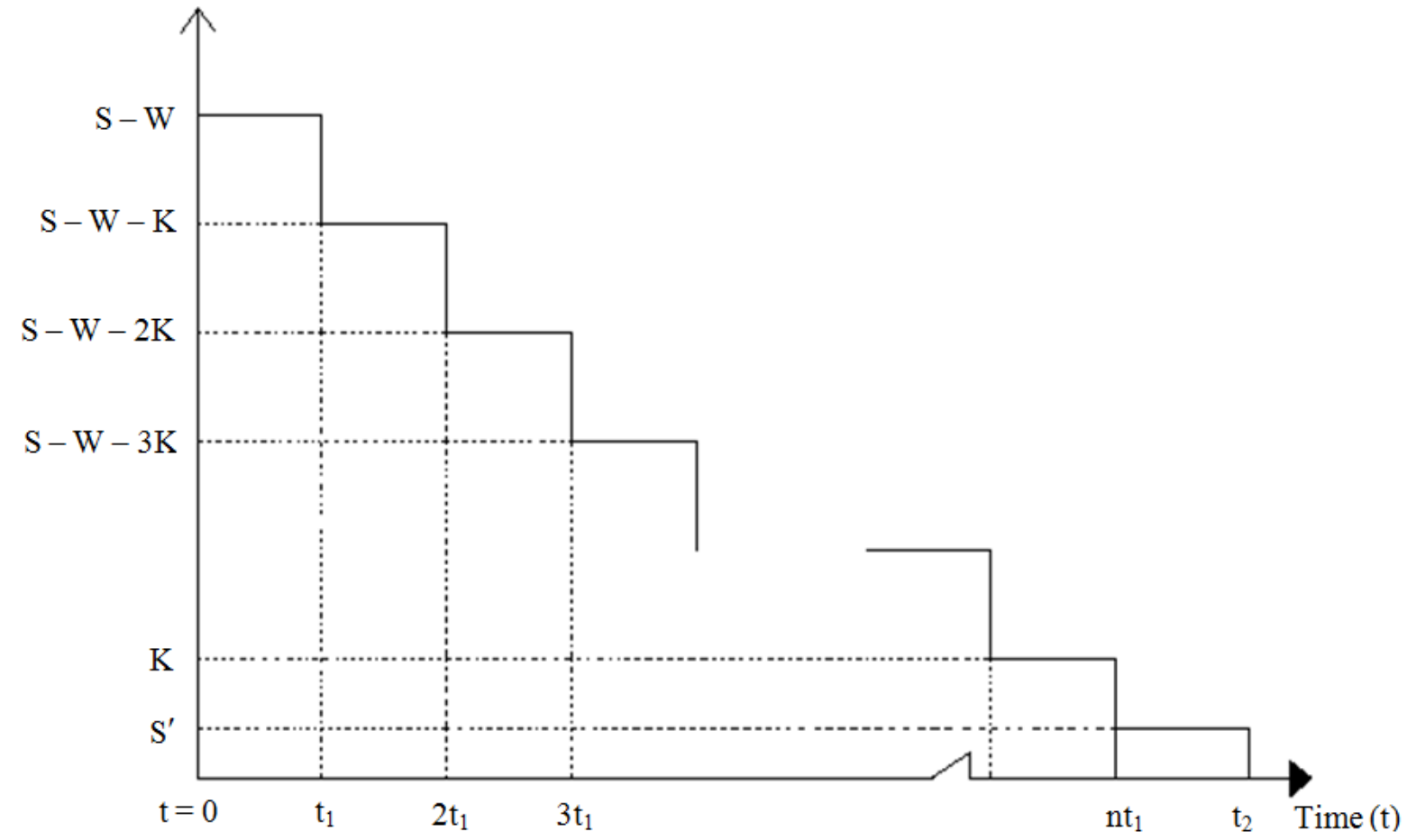

Fig. 1. The inventory situation in RW 


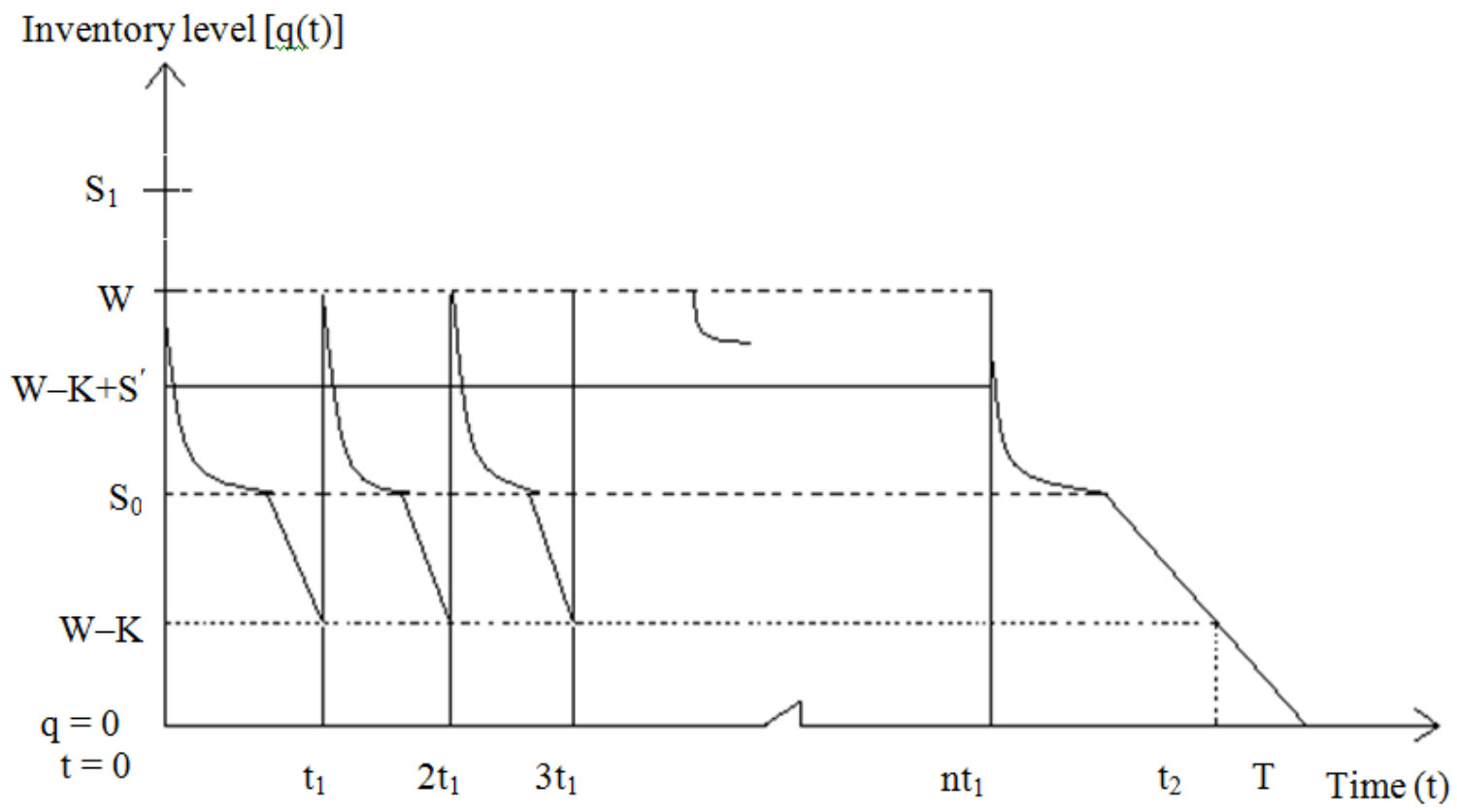

Fig. 2. The inventory situation in OW

As the demands are met only from the owned warehouse (OW), the stock depletion at OW is only due to the demand of the items only. Therefore, the inventory level $q(t)$ at time $t\left(0<t<t_{1}\right)$ satisfies the following differential equations,

$d q(t) / d(t)=\left\{\begin{array}{lcc}-f(A, p, q) & \text { for } & S_{0}<q \leq W \\ -f\left(A, p, S_{0}\right) & \text { for } & q \leq S_{0}\end{array}\right.$

According to the assumption (ix), the relation among $S, K$ and $S^{\prime}$ is given by

$S-W=(n-1) K+S^{\prime}$

Since demand rate is a function of instantaneous displayed stock-level in OW, the time taken for the consumption of $K$ units and the last $W-K+S^{\prime}$ units in OW depends on the stock-level. Therefore we have,

$t_{1}=\int_{S_{0}}^{W} \frac{d q}{f(A, p, q)}+\int_{W-K}^{S_{0}} \frac{d q}{f\left(A, p, S_{0}\right)}$,

and

$t_{2}=\int_{S_{0}}^{W-K+S^{\prime}} \frac{d q}{f(A, p, q)}+\int_{0}^{S_{0}} \frac{d q}{f\left(A, p, S_{0}\right)}$.

Again, the total time period $T$ is given by

$T=n t_{1}+t_{2}$. 
The total cost in a cycle consists of the following components:

(i) Ordering $\operatorname{cost}\left(C_{4}\right)$, (ii) Inventory carrying $\operatorname{cost}\left(C_{\text {hol }}\right)$, (iii) Transportation $\operatorname{cost}\left(C_{\text {tran }}\right)$, (iv) Purchase cost $\left(C_{1} S\right)$, (v) Advertisement cost $\left(C_{a d v}\right)$

The inventory carrying cost per unit time can be expressed as the product of the inventory level and the carrying cost per unit time. Thus, the total inventory carrying cost is given by

$C_{h o l}=C_{f}\left\{n(n-1) K / 2+n S^{\prime}\right\} t_{1}+C_{h}(W-K) n t_{1}+C_{h} b_{1}$,

where $b_{1}=n\left\{\int_{S_{0}}^{W} \frac{q d q}{f(A, p, q)}+\int_{W-K}^{S_{0}} \frac{q d q}{f\left(A, p, S_{0}\right)}\right\}+\int_{S_{0}}^{W-K+S^{\prime}} \frac{q d q}{f(A, p, q)}+\int_{0}^{S_{0}} \frac{q d q}{f\left(A, p, S_{0}\right)}$. The details of the calculations are given in Appendix-A. The total advertisement cost is given by $C_{a d v}=A G$. The total cost of the system (Scenario-1) is given by

$T C=C_{4}+C_{1} S+C_{h o l}+C_{t r a n}+C_{a d v}$.

The net profit for the entire system (Scenario-1) is the difference between the sales per revenue per cycle and the total cost of the system i.e.,

$X=\left(p-C_{1}\right) S-C_{4}-C_{h o l}-C_{t r a n}-C_{a d v}$.

Therefore, for the fixed value of the mark-up rate, the profit function $\pi_{1}(m, n, A, S, K)$ (Average profit per unit time for the cycle) of the inventory system (Scenario-1) is given by

$\pi_{1}(m, n, A, S, K)=X / T$.

Here, the profit function is a function of two continuous variables $S$ and $K$ and three discrete variables $m, n$ and $A$. Hence, the problem is to find the optimal values of $m, n, A, S$ and $K$ by maximizing the profit function $\pi_{1}(m, n, A, S, K)$. Then the optimal values of $S^{\prime}$ and $T$ can be calculated by Eq. (3) and Eq. (6), respectively.

In Scenario-1, let $m^{*}, n^{*}, A^{*}, S^{*}$ and $K^{*}$ be the optimal values of $m, n, A, S$ and $K$. However, this solution is obtained without considering the capacity constraint of RW i.e., $S-W \leq Q_{R}$ as the storage capacity of RW is limited. If $S-W \leq Q_{R}$, it is obvious that $m^{*}, n^{*}, A^{*}, S^{*}$ and $K^{*}$ be the feasible solution of Scenario-1 and $\pi_{1}^{*}=\pi_{1}\left(m^{*}, n^{*}, A^{*}, S^{*}, K^{*}\right)$ be the optimal profit. Otherwise, $\pi_{1}^{*}$ is equal to the optimal boundary profit $\pi_{1}^{*}\left(n^{*}, A^{*}, K^{*}\right)$ when $S=Q_{R}+W$ (in that case, $m$ is fixed and easily be obtained). Now, we shall determine the optimal boundary profit. At first, fixing $S$ by $Q_{R}+W$, then from Eq. (3), we have $Q_{R}=(n-1) K+S^{\prime}$ i.e.,

$S^{\prime}=Q_{R}-(n-1) K$.

In this case, the boundary profit function of Scenario-1 is given by

$$
\begin{aligned}
\pi_{1}^{\prime}(n, A, K) & =\left[\left(p-C_{1}\right)\left(Q_{R}+W\right)-C_{4}-C_{f}\left\{n Q_{R}-n(n-1) K / 2\right\} t_{1}\right. \\
& -C_{h}\left\{n\left(\int_{S_{0}}^{W} \frac{q d q}{f(A, p, q)}+\int_{W-K}^{S_{0}} \frac{q d q}{f\left(A, p, S_{0}\right)}\right)+(W-K) n t_{1}\right.
\end{aligned}
$$




$$
\left.\left.+\int_{S_{0}}^{W-K+S^{\prime}} \frac{q d q}{f(A, p, q)}+\int_{0}^{S_{0}} \frac{q d q}{f\left(A, p, S_{0}\right)}\right\}-C_{\text {tran }}-A G\right] / T .
$$

Clearly, $\pi_{1}^{\prime}$ is a function of $n, A$ and $K$ only.

For the other Scenarios, the profit functions, $\pi_{i}$, where $i$ represents the number of Scenario, are as follows:

$$
\begin{aligned}
& \pi_{i}=\left[\left(p-C_{1}\right) S-C_{4}-C_{f}\left\{n(n-1) K / 2+n S^{\prime}\right\} t_{1}-C_{h}(W-K) n t_{1}-C_{h} b_{i}-C_{\text {tran }}-A G\right] / T, \\
& i=2,3, \cdots, 9
\end{aligned}
$$

where

$$
\begin{aligned}
& b_{2}=n\left\{\int_{S_{0}}^{W} \frac{q d q}{f(A, p, q)}+\int_{W-K}^{S_{0}} \frac{q d q}{f\left(A, p, S_{0}\right)}\right\}+\int_{0}^{W-K+S^{\prime}} \frac{q d q}{f\left(A, p, S_{0}\right)}, \\
& b_{3}=n \int_{W-K}^{W} \frac{q d q}{f(A, p, q)}+\int_{S_{0}}^{W-K+S^{\prime}} \frac{q d q}{f(A, p, q)}+\int_{0}^{S_{0}} \frac{q d q}{f\left(A, p, S_{0}\right)}, \\
& b_{4}=n\left\{\int_{S_{1}}^{W} \frac{q d q}{f\left(A, p, S_{1}\right)}+\int_{S_{0}}^{S_{1}} \frac{q d q}{f(A, p, q)}+\int_{W-K}^{S_{0}} \frac{q d q}{f\left(A, p, S_{0}\right)}\right\}+\int_{S_{1}}^{W-K+S^{\prime}} \frac{q d q}{f\left(A, p, S_{1}\right)} \\
& +\int_{S_{0}}^{S_{1}} \frac{q d q}{f(A, p, q)}+\int_{0}^{S_{0}} \frac{q d q}{f\left(A, p, S_{0}\right)} \\
& b_{5}=n\left\{\int_{S_{1}}^{W} \frac{q d q}{f\left(A, p, S_{1}\right)}+\int_{S_{0}}^{S_{1}} \frac{q d q}{f(A, p, q)}+\int_{W-K}^{S_{0}} \frac{q d q}{f\left(A, p, S_{0}\right)}\right\}+\int_{S_{0}}^{W-K+S^{\prime}} \frac{q d q}{f(A, p, q)}+\int_{0}^{S_{0}} \frac{q d q}{f\left(A, p, S_{0}\right)}, \\
& b_{6}=n\left\{\int_{S_{1}}^{W} \frac{q d q}{f\left(A, p, S_{1}\right)}+\int_{S_{0}}^{S_{1}} \frac{q d q}{f(A, p, q)}+\int_{W-K}^{S_{0}} \frac{q d q}{f\left(A, p, S_{0}\right)}\right\}+\int_{0}^{W-K+S^{\prime}} \frac{q d q}{f\left(A, p, S_{0}\right)}, \\
& b_{7}=n\left\{\int_{S_{1}}^{W} \frac{q d q}{f\left(A, p, S_{1}\right)}+\int_{W-K}^{S_{1}} \frac{q d q}{f(A, p, q)}\right\}+\int_{S_{1}}^{W-K+S^{\prime}} \frac{q d q}{f\left(A, p, S_{1}\right)}+\int_{S_{0}}^{S_{1}} \frac{q d q}{f(A, p, q)}+\int_{0}^{S_{0}} \frac{q d q}{f\left(A, p, S_{0}\right)}, \\
& b_{8}=n\left\{\int_{S_{1}}^{W} \frac{q d q}{f\left(A, p, S_{1}\right)}+\int_{W-K}^{S_{1}} \frac{q d q}{f(A, p, q)}\right\}+\int_{S_{0}}^{W-K+S^{\prime}} \frac{q d q}{f(A, p, q)}+\int_{0}^{S_{0}} \frac{q d q}{f\left(A, p, S_{0}\right)}, \\
& b_{9}=n \int_{W-K}^{W} \frac{q d q}{f\left(A, p, S_{1}\right)}+\int_{S_{1}}^{W-K+S^{\prime}} \frac{q d q}{f\left(A, p, S_{1}\right)}+\int_{S_{0}}^{S_{1}} \frac{q d q}{f(A, p, q)}+\int_{0}^{S_{0}} \frac{q d q}{f\left(A, p, S_{0}\right)} .
\end{aligned}
$$

The solutions of these scenarios along with optimal profit $\pi_{i}^{*}(i=2,3, \cdots, 9)$ can be obtained by the same procedure used in Scenario-1. The optimal solution in this system will be the solution 
corresponding to the maximum average profit (for case $S_{1}>W$ and $S_{1}<W$ ) of the above mentioned Scenarios. Let $\pi^{*}$ be the average profit then

$$
\pi *=\max \pi_{\mathrm{i}}\left\{\begin{array}{l}
i=1,2,3 \quad \text { for } \quad \mathrm{S}_{1}>W \\
i=4, \cdots, 9 \text { for } \quad \mathrm{S}_{1} \geq W
\end{array}\right.
$$

\section{Solution Procedure}

The optimization problem of each scenario is a nonlinear mixed integer programming. To solve the resulted problems, we shall develop hybrid genetic algorithm combining advanced genetic algorithm and multi-section criteria.

\subsection{Hybrid Genetic Algorithm}

When an optimization problem is solved by genetic algorithm (GA), the bounds of the decision variables are required i.e., the optimization problem with known search space can be solved by this method. However, when the search space of an optimization problem is unknown, a large search space is considered. Again, GA does not work properly to find optimal solution or near optimal solution when the search space is large. To overcome the difficulty i.e., for the application of GA with smaller search space, we develop a hybrid algorithm combing advanced GA and multi-section criteria.

\subsection{Multi-section}

Multi-section means using multiple bisection where more than one bisection can be made in a single iteration cycle. In this criterion, the search space is divided into several subspaces of equal size. In case of optimization problem with two decision variables, the search space is a rectangle which can be multi-sectioned into $2^{2}=4$ (double bisection) subspaces. Similarly, in case of optimization problem with three decision variables, the search space can be multi-sectioned into $2^{3}=8$ (triple bisection) subspaces. Thus, in general, if we consider multiple bisection (say $m$ sections) in each direction of the search space, the total number of subspaces will be $m^{n}$ (for optimization problem with $n$-decision variables). The pictorial diagram is shown in Fig 3 for $m=2$ and $n=3$.

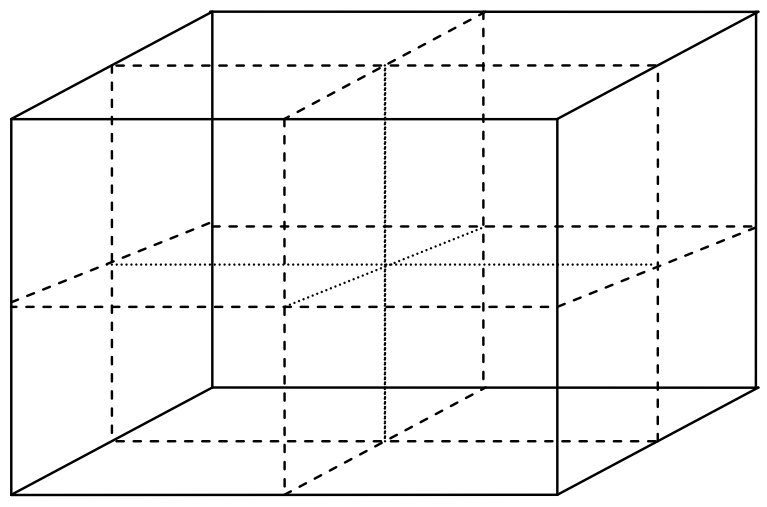

Fig. 3. Multi-section of search space

Multi-splitting is a special type of multi-section where $m$ equal size subspaces are produced. In this case, we can optimize the computation by using the most promising direction (i.e., the direction of the longest edge of the accepted/initial search space for subdivision). This type of multi-section 
where $m$ is the number of subspaces is formed and it will be known as multi-splitting. Fig. 4 shows a special case when $m=4, n=3$.

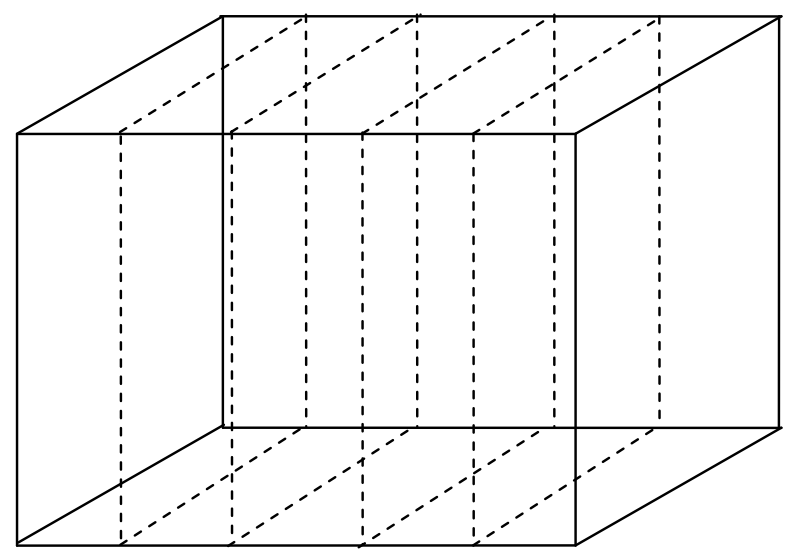

Fig. 4. Multi-splitting of search space

\subsection{Genetic Algorithm}

Genetic Algorithm (GA) is a computerized stochastic search and iterative optimization algorithm based on the mechanics of natural evolution and genetics (Goldberg, 1989; Michalawicz, 1996 and Gen et al., 2000). GA has been successfully applied to different types of optimization problems, for its several advantages over traditional optimization methods. Holland (cf. Holland, 1975) was inspired by Darwin's theory about the natural evolution and then he constructed an evolutionary algorithm based on the fundamental principle of the Darwin's theory: 'Survival of the fittest'. This algorithm is known as genetic algorithm.

To implement the above mentioned GA for the proposed model, the following basic components are considered.

(i) GA parameters

(ii) Chromosome representation for potential solutions to the problem

(iii) Initialization of chromosomes

(iv) Evaluation of fitness function

(v) Selection process

(vi) Genetic operators - crossover and mutation

The implementation of GA depends on different parameters such as population size ( $p \_s i z e$ ), maximum number of generations ( $m_{\_}$gen), probability of crossover ( $p_{-}$cross) and probability of mutation (p_mute). Usually, the crossover rate varies from 0.6 to 0.95 whereas the mutation rate changes from 0.1 to 0.15 . Sometimes, the mutation rate is considered as $1 / n$ where $n$ is the number of genes of the individuals.

For proper and successful functioning of GA, it is important to design an appropriate chromosome for the solutions of the problem. For the initial implementation of GAs, the chromosomes are represented by the strings of binary numbers called binary GAs. These are robust search techniques since they avoid the local optimum but the computational cost is relatively higher than the deterministic optimization techniques. There are a number of difficulties when we seek high precession for problems with large search space. One alternative solution to overcome the difficulties is to use real numbers to represent the chromosomes in GAs. In this case, a chromosome is coded in the form of vector/matrix of integer or floating-point numbers and every component of that chromosome 
represents a decision variable of the problem. This type of GA is known as real coded genetic algorithm (RCGA).

Once a chromosome representation is selected we must initialize the chromosomes which will take part in the artificial genetic operations. The procedure produces population size number of chromosomes in which every component is randomly generated within the bounds of the corresponding decision variable. After initialization of chromosome representation, the next step is to check the fitness of each chromosome. For this purpose, the fitness value for each chromosome is calculated. In our work, the objective function of the problem is considered as the fitness function.

Selection operator is one of the most important features of the genetic algorithm. The process is stochastic and biased towards the best chromosome/solution. The primary objective of this operator is to emphasize on the above average solutions and to eliminate the below average solutions from the population for the next generation based on the well-known evolutionary principle "Survival of the fittest”. There are several selection schemes, such as roulette wheel selection, ranking selection, elitist preserving selection, stochastic universal sampling selection, truncation selection, tournament selection, etc. In our work, we use ranking selection as a selection operator. In this selection process, the population is actually sorted from the best to the worst fashion according to the fitness value of chromosomes. The selection probability of each chromosome is determined according to their ranking.

After the selection process, the resulting chromosomes will be improved by two genetic operations: crossover and mutation. In crossover operation, two or more parent chromosomes are selected at a time and two or more offspring are generated by combining the features of all the parent chromosomes. For this operation, expected [p_cross $\times p \_$size] ([ ] denotes the integral value) number of chromosomes will take part. Here, we perform this operation by selecting two parent chromosomes at a time. The different steps of crossover operations are as follows:

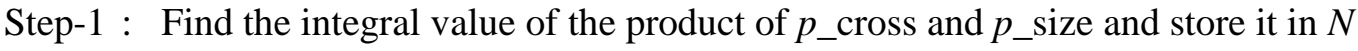

Step-2 : Select the chromosomes $V_{j}$ and $V_{k}$ randomly from the population

Step-3 : Generate a random real number $\lambda$ in $[0,1]$

Step-4 : The $i$-th component $V_{j i}^{\prime}$ and $V_{k i}^{\prime}$ of two offspring corresponding to continuous (non-integer) variable will be created by

$$
\begin{aligned}
& V_{j i}^{\prime}=\lambda V_{j i}+(1-\lambda) V_{k i} \\
& V_{k i}^{\prime}=\lambda V_{k i}+(1-\lambda) V_{j i}
\end{aligned}
$$

Step-5 : The l-th component $V_{j l}^{\prime}$ and $V_{k l}^{\prime}$ corresponding to integer variable will be created by either

$$
V_{j l}^{\prime}=V_{j l}-g \text { and } V_{k l}^{\prime}=V_{k l}+g \text { if } V_{j l}>V_{k l}
$$

or, $V_{j l}^{\prime}=V_{j l}+g$ and $V_{k l}^{\prime}=V_{k l}-g$, otherwise

where $g$ is a random integer number between 0 and $\left|V_{j l}-V_{k l}\right|$.

Step-6 : Repeat Step-2 to Step-5 for $\frac{N}{2}$ times 
The primary objective of the mutation operator is to introduce the genetic diversity of the population. This operator is used to enhance the fine tuning capabilities of the system. This is implemented to a single chromosome only with lower probability. By modifying one or more of the gene values of an existing parent chromosome, mutation creates new offspring, increasing the variability of the population. We perform this operation on single gene by using non-uniform mutation for non-integer variable or by considering a random integer number between the bounds of the integer variables.

\section{Numerical Result}

To illustrate the proposed model, a numerical example is considered. The values of model parameters considered are not collected from any case study, but these values are considered to be realistic.

\section{Example:}

Let $C_{4}=200, C_{h}=1, C_{f}=1.5, C_{1}=20, \lambda=1.3, W=100, Q_{r}=700, a=500, \quad b=0.5$,

$c=0.3, \mathrm{~S}_{1}=150$ (in case of $\mathrm{S}_{1}>W$ ), $\mathrm{S}_{1}=75$ (in case of $\mathrm{S}_{1}<W$ ),

$S_{0}=50, G=50, a^{\prime}=20, b^{\prime}=0.5, P^{\prime}=20, \gamma=0.2, C_{a d}=0.2, K^{\prime}=100$,

$C_{t}=100, C_{t F}=1.25$ for $\mathrm{L}=90$ in appropriate units.

This example was solved to find the best found values of $S, K, S^{\prime}, T, A, m, n$ along with the best found profit per unit time of the system. For this purpose, 20 independent runs were performed by the proposed hybrid GA. Also, to test the performance of our developed hybrid GA to solve the problems for each scenario, best found value, mean, median and standard deviation for 20 independent runs have been computed. Table 1 and Table 2 summarize the details of the implementation. In this computation, the following values of GA parameters are used:

$$
\text { p_size }=200, \quad m \_ \text {gen }=500, \text { p_cross }=0.8, \text { p_mute }=0.15
$$

All the simulations have been conducted on a PC with Intel Core-2 duo processor, 1 GB RAM and 2.0 GHz speed.

Table 1

Computational results of different scenarios of the proposed model

\begin{tabular}{lllll}
\hline \multirow{2}{*}{$\begin{array}{l}\text { Scenario } \\
\text { Best found profit } \\
\text { value }\end{array}$} & \multicolumn{2}{l}{ Statistical characteristics of profit value } \\
\cline { 3 - 5 } & Mean & Median & $\begin{array}{l}\text { Standard } \\
\text { Deviation }\end{array}$ \\
\hline 1 & 2157.27 & 2157.25 & 2157.26 & 0.01440 \\
\hline 2 & 2143.11 & 2143.11 & 2143.11 & 0.0 \\
3 & 2074.74 & 2074.54 & 2074.56 & 0.13998 \\
4 & 2152.40 & 2152.40 & 2152.40 & 0.00115 \\
5 & 2135.52 & 2135.52 & 2135.52 & 0.0 \\
6 & 2138.23 & 2138.23 & 2138.23 & 0.0 \\
\hline 7 & 2065.77 & 2065.70 & 2065.74 & 0.06399 \\
\hline 9 & 2051.95 & 2051.94 & 2051.95 & 0.01832 \\
\hline
\end{tabular}


Table 2

Performance analysis of different scenarios

\begin{tabular}{lllllllll}
\hline \multirow{2}{*}{ Scenario } & \multicolumn{7}{c}{ Performance analysis of different scenarios } \\
\cline { 2 - 9 } & $\mathrm{S}$ & $\mathrm{K}$ & $\mathrm{S}^{\prime}$ & $\mathrm{T}$ & $\mathrm{A}$ & $\mathrm{m}$ & $\mathrm{n}$ & $\mathrm{Z}$ \\
\hline 1 & 700.00 & 100.00 & 100.00 & 0.8920 & 9 & 7 & 7 & 2157.27 \\
2 & 700.00 & 96.67 & 20.00 & 0.8920 & 9 & 7 & 8 & 2143.11 \\
3 & 700.00 & 50.00 & 50.00 & 0.8863 & 9 & 7 & 14 & 2074.74 \\
4 & 700.00 & 100.00 & 100.00 & 0.8936 & 9 & 7 & 7 & 2152.40 \\
5 & 700.00 & 92.86 & 42.86 & 0.8936 & 9 & 7 & 8 & 2135.52 \\
6 & 700.00 & 96.67 & 20.00 & 0.8936 & 9 & 7 & 8 & 2138.23 \\
7 & 700.00 & 50.00 & 50.00 & 0.8893 & 9 & 7 & 14 & 2065.77 \\
8 & 700.00 & 48.08 & 23.08 & 0.8891 & 9 & 7 & 15 & 2051.95 \\
9 & 700.00 & 24.99 & 24.99 & 0.8865 & 9 & 7 & 28 & 1922.80 \\
\hline
\end{tabular}

\section{Sensitivity Analysis}

Considering the earlier mentioned example, sensitivity analyses have been performed graphically to study the effect of changes of different parameters on the best found average profit of the proposed problem. These analyses have been carried out by changing, increasing and decreasing, the parameters from $-20 \%$ to $+20 \%$, taking one or more parameters at a time and keeping the others at their original values. In each case, the best found value of the optimal profit has been considered from 20 independent runs and the results are shown by Fig. 5 to Fig. 8.

From Fig. 5 and Fig. 7, it is observed that the best found profit is insensitive with respect to the parameters like holding costs ( $C_{h}, C_{f}$ and both) in OW and RW, ordering cost $\left(C_{4}\right)$, capacity of the show-room (W) and the shape parameters $(b, c)$. On the other hand, from Fig. 6 to Fig 8., it is clear that the best average profit is more sensitive with respect to the location parameter $(a)$ of demand, all demand parameters $(a, b, c, \gamma)$, purchase cost $\left(C_{1}\right)$ and all cost parameters. For these cases, for $20 \%$ increase (or decrease) of the said parameters, the average profit is increased (or decreased) by $40 \%$ or more.

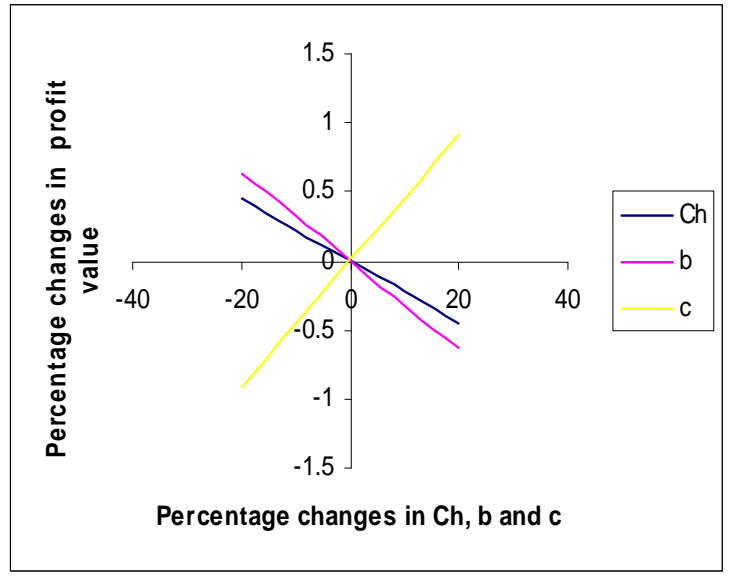

Fig. 5.

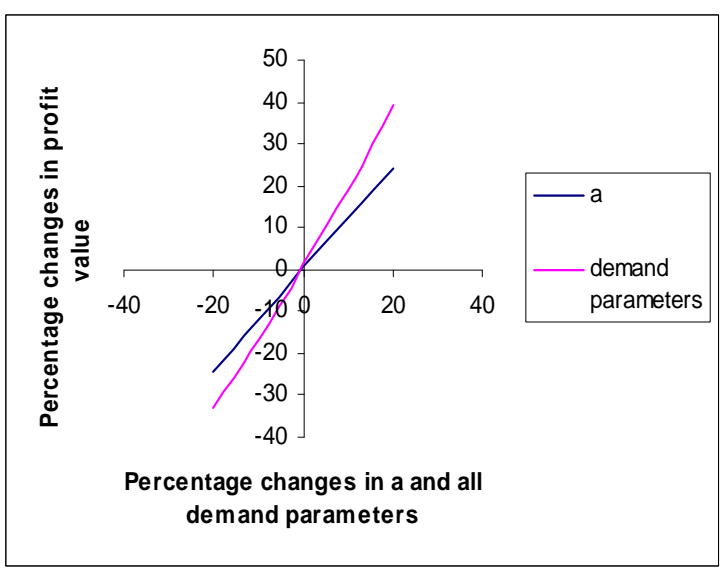

Fig. 6. 


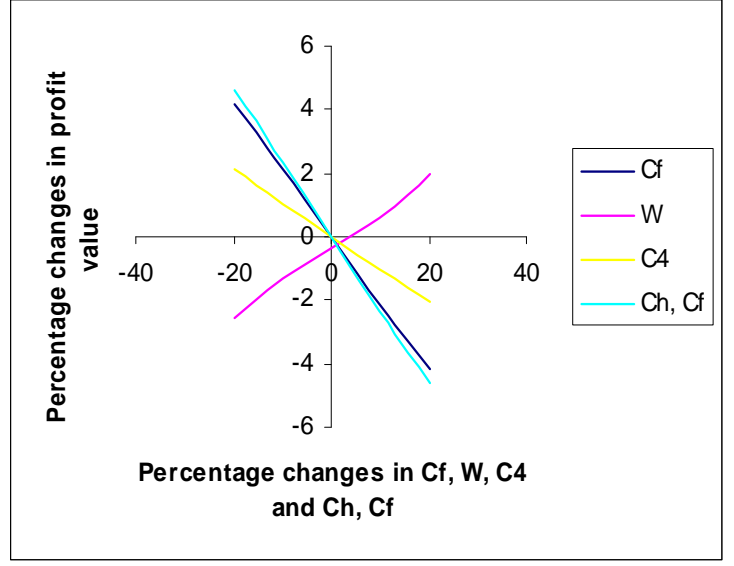

Fig. 7.

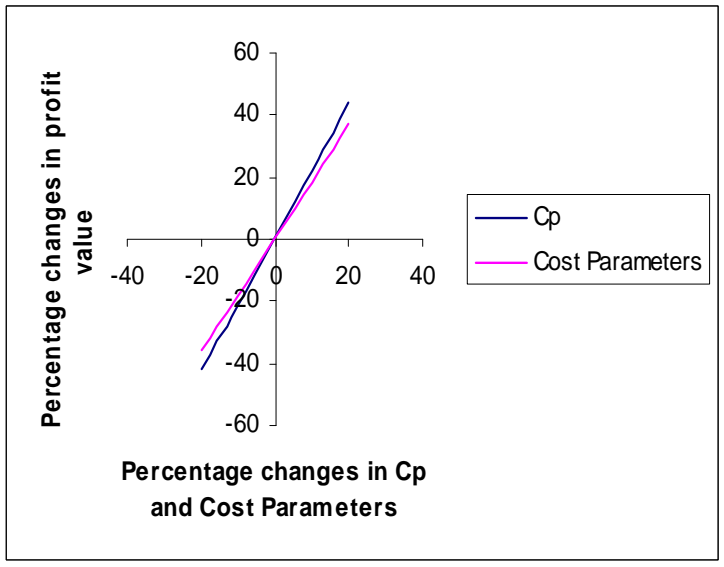

Fig. 8.

\section{Concluding Remarks}

In this paper, a deterministic two-storage inventory model for single item has been developed by removing the unrealistic assumption "The storage capacity of rented warehouse is unlimited" considered in the existing literature. This model has been formulated for single non-deteriorated items considering different scenarios based on the stock dependency factors in the proposed demand rate, storage capacity of show-room and the order quantity of the system.

Another feature of this paper is the consideration of a new type of demand rate which depends on the frequency of advertisement of the item in the popular electronic and print media, selling price of the item and displayed stock level in the show-room. The proposed model of this paper can be seen in the situations where the customers arrive to purchase goods attracted by advertisement and glamorous display of goods in a show-room. This effect continues within a certain range of displayed inventory level in the show-room and beyond the upper level it will be constant. Also, beyond the lower level, only a limited numbers, may be considered as constant, of customers arrive to purchase the goods due to goodwill of the shop, good quality, genuine price of goods, locality of the shop, etc.

The proposed two-storage inventory model can be applied in several practical situations. Presently, due to the introduction of open market policy, the business is becoming more competitive and to attract more customers, a better purchasing environment such as well-decorated show-room with modern light and electronic arrangements and enough free space for choosing items is needed. However, the physical expansion of the show-room may need significant amount of investment. As a result, the authority of departmental store is limited to hire a separate storage on rental basis at a distance place for storing of excess items. Hence, from the economic point of view, the proposed twostorage system is more beneficial than the single storage system.

For future research work in this area, one can extend the model considering quantity discount policy, stochastic demand, multiple and deteriorating items.

\section{Appendix A}

The inventory time units in RW is

$$
(S-W) t_{1}+(S-W-k) t_{1}+(S-W-2 k) t_{1}+\ldots+S^{\prime} t_{1}=\left\{n(n-1) K / 2+n S^{\prime}\right\} t_{1}
$$

and hence the inventory carrying cost for these units in RW is $C_{f}\left\{n(n-1) K / 2+n S^{\prime}\right\} t_{1}$. Between (i1)-th and $i$-th $(i=1,2, \ldots n)$ shipment for transferring items /goods from RW to OW, only $K$ units in 
OW are used to meet the demand and the rest $(W-K)$ units are kept unused in OW for a period of length $\left(t_{i}^{\prime}-t_{i-1}^{\prime}\right)$ i.e, $t_{1}$. Therefore, the inventory carrying cost for these items in OW is as follows,

$C_{h}\left\{\int_{S_{0}}^{W} \frac{q d q}{f(A, p, q)}+\int_{W-K}^{S_{0}} \frac{q d q}{f\left(A, p, S_{0}\right)}+(W-K) t_{1}\right\}$.

Again, when the last shipment arrives in OW, the on-hand inventory in OW becomes $W-K+S^{\prime}$. The inventory carrying cost for these units during usage in OW is as follows,

$C_{h}\left\{\int_{S_{0}}^{W-K+S^{\prime}} \frac{q d q}{f(A, p, q)}+\int_{0}^{S_{0}} \frac{q d q}{f\left(A, p, S_{0}\right)}\right\}$.

Hence, the total inventory carrying cost in OW is

$C_{h}\left[n\left\{\int_{S_{0}}^{W} \frac{q d q}{f(A, p, q)}+\int_{W-K}^{S_{0}} \frac{q d q}{f\left(A, p, S_{0}\right)}\right\}+(W-K) n t_{1}+\int_{S_{0}}^{W-K+S^{\prime}} \frac{q d q}{f(A, p, q)}+\int_{0}^{S_{0}} \frac{q d q}{f\left(A, p, S_{0}\right)}\right]$

\section{Acknowledgement}

The first author would like to acknowledge the support of CSIR (Council of Scientific and Industrial Research), India, for conducting this work.

\section{References}

Abad, P. L. (1996). Optimal pricing and lot-sizing under conditions perishability and partial backordering. Management Science ,42, 1093-1104.

Anily, S. \& Federgruen, A. (1990). One warehouse multiple retailer systems with vehicle routing costs. Management Sciences ,36, 92- 114.

Baker, R. C., \& Urban, T. L. (1985). A deterministic inventory system with an inventory-leveldependent demand rate. Journal of Operational Research Society, 39, 823-831.

Baumol, W. J., \& Vinod, H.C. (1970). An inventory theoretic model of freight transport demand. Management Science 16, 413-421.

Benkherouf, L. (1997). A deterministic order level inventory model for deteriorating items with two storage facilities, International Journal of Production Economics ,48, 167-175.

Bhunia, A. K. \& Maiti, M. (1994). A two warehouse inventory model for a linear trend in demand. Opsearch ,31, 318-329.

Bhunia, A. K. \& Maiti, M. (1995). A deterministic two storage inventory model for variable production and inventory level dependent demand rate. Cashiers du Cero,37,17-24.

Bhunia, A.K. \& Maiti, M. (1998). A two warehouse inventory model for deteriorating items with a linear trend in demand and shortages. Journal of Operational Research Society ,49, 289-292.

Buffa, F., \& Munn, J. (1989). A recursive algorithm for order cycle time that minimizes logistics cost. Journal of Operational Research Society, 40, 367-377.

Constable, G. K., \& Whybark, D. C. (1978). Interactions of transportation and inventory decisions, Decision Sciences, 9, 688-699.

Das, B., Maity, K., \& Maiti, M. (2007). A two warehouse supply chain model under possibility/ necessity/ credibility measures. Mathematical and Computer Modeling, 46, 398-409.

Datta, T. K., \& Pal, A. K. (1990). A note on an inventory model with inventory level-dependent demand rate. Journal of Operational Research Society, 41, 971-975.

Dave, U. (1988). On the EOQ models with two levels of storage, Opsearch, 25, 190-196. 
Dey, J. K., Mondal, S. K., \& Maiti, M. (2008). Two storage inventory problem with dynamic demand and interval valued lead-time over finite time horizon under inflation and time-value of money, European Journal of Operational Research, 185, 170-194.

Dye, C.Y., Ouyang, L. Y., \& Hsieh, T. P. (2007). Deterministic inventory model for deteriorating items with the capability constraint and time-proportional backlogging rate. European Journal of Operational Research, 178, 789-807.

Gen, M. \& Cheng, R. (2000). Genetic Algorithms and Engineering Optimization. John Wiley \& Sons Inc.

Giri, B. C., \& Chaudhuri, K. S. (1998). Deterministic models for perishable inventory with stock dependent demand rate and non-dependent holding cost. European Journal of Operational Research, 105, 467-474.

Giri, B. C., Pal, S., Goswami, A \& Chaudhuri, K. S. (1996). An inventory model for deteriorating items and stock-dependent demand rate. European Journal of Operational Research, 95, 604-610.

Goldberg, D. E. (1989). Genetic Algorithms: Search, Optimization and Machine Learning; Addison Wesley.

Goswami, A. \& Chaudhuri, K. S. (1992). An economic order quantity model for items with two level of storage for a linear trend in demand. Journal of Operational Research Society, 43, 157-167.

Goyal, S. K., \& Gunasekaran, A. (1995). An integrated production - inventory marketing model for deteriorating items. Computers and Industrial Engineering, 28, 755-762.

Hartely, R.V. (1976). Operations Research- A Managerial Emphasis., Good Year Publishing Company, California, 315-317.

Holland, J. H. (1975). Adaptation of Natural and Artificial system, University of Michigan Press, Ann Arbor.

Jaggi, C. K. \& Arneja, N. (2011). Stochastic integrated vendor-buyer model with unstable lead time and setup cost. International Journal of Industrial Engineering Computations, 2(1), 123-140.

Kar, S., Bhunia, A. K., \& Maiti, M, (2001). Deterministic inventory model with levels of storage, a linear trend in demand and a fixed time horizon. Computer and Operations Research, 28, 13151331.

Kotler, P. (1971). Marketing Decision Making: A Model Building Approach. Holt. Rinehart, Winston, New York .

Ladany, S., \& Sternleib, A. (1974). The intersection of economic ordering quantities and marketing policies, AIIE Transactions, 6, 35-40.

Luo, W. (1998). An integrated inventory system for perishable goods with backordering. Computers and Industrial Engineering, 34, 685-693.

Mandal, B.N., \& Phaujdar, S. (1989). An inventory model for deteriorating items and stock-dependent consumption rate. Journal of Operational Research Society, 4, 483-488.

Michalawicz, Z. (1996). Genetic Algorithms + Data structure= Evaluation Programs. Springer Verlog, Berlin.

Mondal, B., Bhunia, A. K., \& Maiti, M. (2007). A model of two storage inventory system under stock dependent selling rate incorporating marketing decisions and transportation cost with optimum release rule. Tamsui oxford journal of mathematical sciences, 23(3), 243-267.

Niu, B., \& Xie, J. (2008). A note on Two-warehouse inventory model with deterioration under FIFO dispatch policy. European Journal of Operational Research, 190, 571-577.

Padmanabhan, G., \& Vrat, P., (1995). EOQ models for perishable items under stock-dependent selling rate. European Journal of Operational Research, 86, 281-292.

Pakkala, T. P. M., \& Achary, K. K. (1992-a). A deterministic inventory model for deteriorating items with two warehouses and finite replenishment rate. European Journal of Operational Research , 57, 71-76.

Pakkala, T. P. M., \& Achary, K. K. (1992-b). Discrete time inventory model for deterministic inventory model for deteriorating items with two warehouses, Opsearch, 29 (1992-b), 90-103. 
Pal, A. K., Bhunia, A.K., \& Mukherjee, R.N. (2004). A marketing-oriented inventory model with threecomponent demand rate dependent on displayed stock level (DSL). Journal of the Operational Research Society, 56, 113-118.

Pal, A. K., Bhunia, A. K., \& Mukherjee, R. N. (2006). Optimal lot size model for deteriorating items with demand rate dependent on displayed stock level(DSL) and partial backordering. European Journal of Operational Research ,175, 977-991.

Pal, P., Das, B., Panda, A. \& Bhunia, A. K. (2005). An application of real-coded genetic algorithm for mixed integer non-linear programming in an optimal two-warehouse inventory policy for deteriorating items with a linear trend in demand and a fixed planning horizon. International Journal of Computer Mathematics, 82(2), 167-175.

Pal, S., Goswami, A. \& Chaudhuri, K. S., (1993). A deterministic inventory model for deteriorating items and stock-dependent demand rate. International Journal of Production Economics, 32, 291299.

Rong, M., Mahapatra, N. K., \& Maiti, M. (2008). A two warehouse inventory model for a deteriorating item with partially/ full backlogged shortage and fuzzy lead time. European Journal of Operational Research, 189, 69-75.

Sarkar, B. R., Mukherjee, S., \& Balan, C. V., (1997). An order-level lot-size inventory model with inventory-level dependent demand and deterioration. International Journal of Production Economics, 48, 227-236.

Sarma, K. V. S. (1983). A deterministic inventory model with two levels storage and an optimum release rule. Opsearch, 20, 175-180.

Sarma, K. V. S. (1983). A deterministic order-level inventory model for deteriorating items with two storage facilities. European Journal of Operational Research ,29, 70-72.

Subramanyam, S., \& Kumaraswamy, S. (1981). EOQ formula under varying marketing policies and conditions. AIIE Transtions ,13, 312-314.

Urban, T. C. (1992). Deterministic inventory models incorporating marketing decisions. Computers \& Industrial Engineering, 22, 85-93.

Urban, T. L. (1995). Inventory models with the demand rate dependent on stock and shortage levels. International Journal of Production Economics ,40, 21-28.

Yang, H. L. (2004). Two-warehouse inventory models for deteriorating items with shortages under inflation. European Journal of Operational Research, 157, 344-356.

Yang, H. L. (2006). Two-warehouse partial backlogging inventory models for deteriorating items under inflation. International Journal of Production Economics, 103, 362-370.

Zhou, Y. W. (2003). A multi-warehouse inventory model for items with time-varying demand and shortages. Computers \& Operations Research, 30, 2115-2134.

Zhou,Y. W. \& Yang, S. L. (2003). A two-warehouse inventory model for items with stock-leveldependent demand rate. International Journal of Production Economics, 95, 215-228.

Zhou,Y. W., (1998). An optimal EOQ model for deteriorating items with two warehouses and time varying demand. Mathematica Applicata, 10, 19-23. 